\title{
Promoter hypomethylation, especially around the E26 transformation-specific motif, and increased expression of poly (ADP-ribose) polymerase 1 in BRCA-mutated serous ovarian cancer
}

Fang-Fang $\mathrm{Bi}^{1+}, \mathrm{Da} \mathrm{Li}^{1,2+}$ and Qing Yang ${ }^{1 *}$

\begin{abstract}
Background: Poly (ADP-ribose) polymerase 1 (PARP1) overexpression plays a critical role in ovarian cancer progression and the clinical development of PARP1 inhibitors to treat BRCA-mutated ovarian cancer has advanced rapidly. However, the mechanism regulating PARP1 expression remains unknown. Alterations in gene expression mediated by promoter methylation are being increasingly recognized and have frequently been reported in ovarian cancer. We therefore investigated the methylation status of the PARP1 promoter region and its correlation with PARP1 expression in BRCA-mutated ovarian cancer.
\end{abstract}

Methods: DNA from BRCA-mutated serous ovarian cancer samples and adjacent normal ovarian tissues were analyzed by bisulfite sequence using primers focusing on the $\mathrm{CpG}$ island in the promoter region of PARP1. Expression levels of PARP1 were assessed by immunohistochemistry and real-time PCR.

Results: Serous ovarian cancer tissues displayed decreased DNA methylation in the promoter region of PARP1 compared to normal tissue, and methylation intensity correlated inversely with PARP1 mRNA levels. More importantly, E26 transformation-specific (ETS) defined CpG sites were significantly less methylated in ovarian cancer samples.

Conclusions: These results indicate that hypomethylation of the promoter region, especially around the ETS motif might play a role in the upregulation of PARP1 expression in the progression of ovarian cancer.

Keywords: PARP1, ETS, BRCA mutation, Ovarian cancer, Methylation

\section{Background}

Ovarian cancer is the most lethal gynecological malignancy in the United States [1]. To date, although the exact cause of ovarian cancer is not clear, BRCA1 and BRCA 2 mutations are the only known causes of hereditary ovarian cancer [2]. In 2005, two pivotal studies showed that BRCA-deficient cells were especially sensitive to chemical inhibitors of poly (ADP-ribose) polymerase (PARP), which plays a critical role in singlestranded DNA break repair, presumably due to the lack

\footnotetext{
* Correspondence: biff@yahoo.cn

${ }^{\dagger}$ Equal contributors

'Department of Obstetrics and Gynecology, Shengjing Hospital, China Medical University, Shenyang 110004, China

Full list of author information is available at the end of the article
}

of homologous recombination-dependent DNA repair $[3,4]$. These findings have raised significant concerns about PARP and PARP inhibitors in ovarian cancer. Recently, emerging evidence has indicated that PARP expression is frequently upregulated in ovarian cancer and is related to worse overall survival [5,6]. However, little is known about the mechanisms regulating PARP gene transcription. In mammals, methylation of cytosine in CpG dinucleotides (especially those located in promoter regions) is an important feature regulating gene expression [7]. Notably, Several lines of data have suggested that PARP1 promoter methylation is involved in the regulation of nano-SiO2-induced decrease of PARP1 expression in $\mathrm{HaCaT}$ cells [8] and benzene-induced decrease of PARP1 expression in lymphoblastoid cell line 
F32 [9]. Our present study is the first to analyze DNA methylation patterns in the PARP1 promoter region in BRCA-mutated ovarian cancer, showing that abnormal hypomethylation of this promoter, especially around the E26 transformation-specific (ETS) motif, may be responsible for PARP1 overexpression.

\section{Methods}

\section{Patients}

This study was approved by the Institutional Review Board at China Medical University. Serous ovarian cancer patients were enrolled between 2010 and 2012, and all patients gave informed consent. Fresh tumor samples, adjacent normal ovarian tissues and blood samples were obtained at the time of primary surgery before any chemotherapy or radiotherapy. Hematoxylin and eosin staining of the samples for histopathological diagnosis and grading were determined by three staff pathologists using the World Health Organization criteria. All patients were screened for BRCA1 and 2 mutations by multiplex polymerase chain reaction with complete sequence analysis as previously reported [10-12]. Briefly, genomic DNA isolated from peripheral blood leukocytes were amplified using specific primers and the amplified products were then sequence analyzed. At the end, ten patients were determined to have a BRCA-mutation. Their characteristics are given in Additional file 1.

\section{Real-time quantitative PCR}

Total RNA was extracted from the tumor and normal ovarian tissues using Trizol reagents (Invitrogen, Carlsbad, CA) according to the manufacturer's protocol. It was then reverse transcribed using the PrimeScript RT Master Mix kit (TaKaRa, Dalian, China) and amplified by SYBR Premix Ex TaqTM II (TaKaRa) in a Roche LightCycler 2.0 instrument (Roche Diagnostics, Mannheim, Germany). The specific primer sequences were as follows: PARP1: 5'- GAGTCGGCGATCTTGGACC - $3^{\prime}$ (F) and $5^{\prime}$ - TGACCCGAGCATTCCTCG -3' (R); GAPDH: 5'- AGGTGAAGGTCGGAGTCA - $3^{\prime}(\mathrm{F})$ and $5^{\prime}$ - GGTC ATTGATGGCAACAA -3'(R). GAPDH mRNA was amplified as an internal control for normalization of each sample. The PCR cycling conditions were: 45 cycles of $10 \mathrm{~s}$ at $95^{\circ} \mathrm{C}, 20 \mathrm{~s}$ at $60^{\circ} \mathrm{C}$. For all transcripts, the melting curve was obtained after cycling at a stepwise increase in temperature from 55 to $95^{\circ} \mathrm{C}$ to verify the specificity of amplification. The threshold cycle $(\mathrm{Ct})$ was used to represent the relative mRNA amounts. All samples were analyzed in triplicate using the $2^{-\Delta \Delta \mathrm{CT}}$ method.

\section{Immunohistochemistry}

The standard SP kit (Zhongshan, Beijing, China) was used for immunohistochemical staining. Briefly, serial $4-\mu \mathrm{m}$ sections were obtained from each paraffin-embedded tissue block. Following deparaffinization and rehydration, sections were subjected to microwave antigen retrieval. The primary antibody was mouse monoclonal anti-PARP1 (1:100; Santa, Cruz Biotechnologies, USA) and the sections were incubated overnight at $4^{\circ} \mathrm{C}$ with this antibody. 3, 3'-diaminobenzidine (DAB) was used as the chromogen. Nuclei were counterstained with hematoxylin, and slides were dried and mounted. Negative controls were incubated with phosphate-buffered saline (PBS) instead of the antibody. Immunostaining was evaluated by two independent pathologists, blinded to the identity of subject groups. Area quantification was made with a light microscope at a magnification of $400 \times$ and analyzed by Image-Pro Plus 6.0 (Media 2 Cybernetics, USA) using PARP1-positive cells.

\section{Bisulfite sequencing}

Genomic DNA extracted from ovarian carcinoma and normal ovarian tissues with a TIANamp Genomic DNA kit (Tiangen biotech, Beijing, China) was subjected to bisulfite conversion using the EZ DNA MethylationDirect kit (Zymo research, Orange, USA) following the manufacturer's instructions, the conversion efficiency was estimated to be at least $99.6 \%$. It was then amplified by nested PCR. After gel purification, cloning and transformation into E.coli Competent Cells JM109 (TaKaRa), ten positive clones of each sample were sequenced to ascertain the methylation patterns of each $\mathrm{CpG}$ locus. The following primers were used: round I, F: $5^{\prime}$ - TTGGGAT AGAATAATTAAAG $-3^{\prime}$ and R: $5^{\prime}$ - AACTTTTCCTACA ACATCAA -3'; and round II, F: 5' - TAGAATAATTA AAGGGGTGG $-3^{\prime}$ and R: $5^{\prime}$ - ACAACATCAACAAAA CCTT $-3^{\prime}$. The conditions were as follows: $95^{\circ} \mathrm{C}$ for $2 \mathrm{~min}$, 40 cycles of 30 s at $95^{\circ} \mathrm{C}, 30 \mathrm{~s}$ at $56^{\circ} \mathrm{C}$ and $45 \mathrm{~s}$ at $72^{\circ} \mathrm{C}$, then $72^{\circ} \mathrm{C}$ for $7 \mathrm{~min}$.

\section{Statistical analysis}

The data are presented as mean \pm SD. Statistical differences in the data were evaluated by paired Student's $t$ test, and were considered significant at $P<0.05$.

\section{Results}

PARP1 expression was upregulated in BRCA-mutated ovarian cancer

Real-time PCR and immunohistochemical analysis showed that PARP1 mRNA and protein were overexpressed in ovarian cancer tissues, compared to normal ovarian tissues $(P<0.05$; each group $\mathrm{n}=10$; Figure $1 \mathrm{~A}$ and $\mathrm{B})$.

\section{BRCA-mutated ovarian cancer tissues displayed a highly} hypomethylated ETS motif and promoter region

To investigate PARP1 transcriptional regulation through epigenetic mechanisms, we assessed the essential regulatory region by analyzing changes in the methylation of 

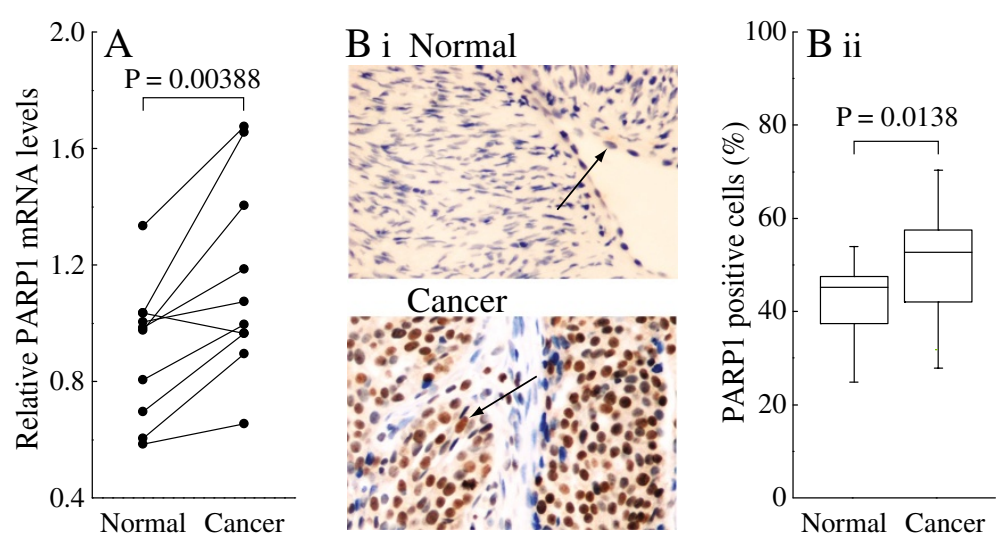

Figure 1 Overexpression of PARP1 mRNA and protein in BRCA-mutated ovarian cancer. A, Relative PARP1 mRNA levels were measured by real-time quantitative PCR. B i, Sections were subjected to immunostaining for PARP1 in normal and ovarian cancer tissue. Arrow shows positive staining for PARP1 in the nuclei. $\mathbf{B}$ ii, Summary of the percentages of PARP1-positive cells from the measurements shown in (B i). Bar graphs show mean \pm SD. Magnification is $400 \times$.

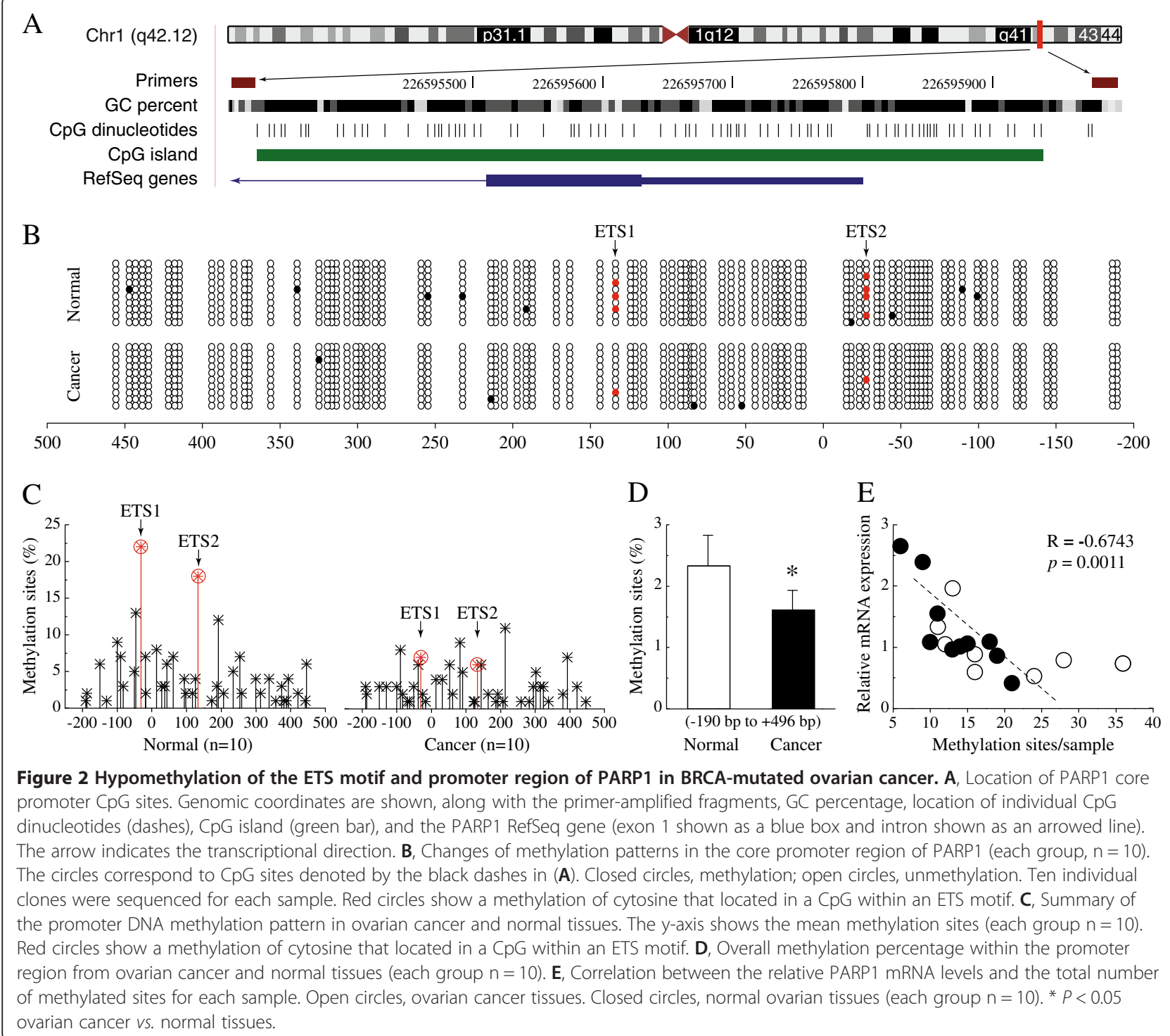


important transcription factor-binding sites. As shown in Figure $2 B$ and $C$, we searched for differences in the DNA methylation pattern between ovarian cancer and normal tissues. Bisulfite sequence analysis showed that ovarian cancer tissues exhibited global hypomethylation, especially around the ETS motif. The total percentage of promoter methylated sites in this region $(-190$ to +496$)$ was significantly decreased in ovarian cancer compared to normal tissues $(P<0.05$; Figure $2 \mathrm{D})$. In addition, we noted a significant negative correlation between PARP1 mRNA levels and the total number of methylated sites in both ovarian cancer and normal tissues (Figure 2E).

\section{Discussion}

DNA methylation is an epigenetic phenomenon known to play a critical role in regulating gene expression through interference with the binding of specific transcription factors to recognition sites in promoters [13]. ETS is one of the largest transcription factor families and has a highly conserved DNA-binding domain that recognizes a common sequence motif, 5'-(C/A) GGA (A/T) -3' [14], which is widely distributed in the PARP1 promoter [15]. The present study showed that BRCA-mutated ovarian cancer displayed a relatively hypomethylated PARP1 promoter, but significantly higher methylation as noted particularly around the ETS motif in normal ovarian tissue. Therefore, we speculate that the important mechanism underlying increased PARP1 expression might be related to the abnormal methylation of CpG sites in the ETS motif, thereby affecting the binding of ETS transcription factors. Previous studies have shown that ETS transcription factors may be key mediators in regulating PARP expression [15]. Furthermore, an increasing amount of evidence suggests that ETS transcription factors are important regulators of the tumorigenic properties of ovarian cancer cells [16] and correlate poor survival in serous ovarian carcinoma [17]. Based on these findings, there are some interesting issues that need to be considered in future studies. PARP1 can enhance DNA methyltransferase 1 (DNMT1) expression by maintaining the unmethylated state of the DNMT1 promoter [18], so it can be predicted that up-regulation expression of DNMT1 may be beneficial in resisting genome-wide demethylation during the progression of ovarian cancer. Moreover, PARP1, as the protein component of chromatin, controls transcription through affecting the chromatin structure [19]. Therefore, PARP1 overexpression may constitute a specific epigenetic mark in BRCA-mutated ovarian cancer. Another report indicated that hypermethylation of the BRCA1 promoter correlated with gene inactivation in sporadic breast and ovarian tumors, as inherited BRCA1 mutations [20]. Thus, it is important for future studies to analyze DNA methylation patterns of the PARP1 promoter in the DNA methylation- associated inactivation of the BRCA1 gene in ovarian cancer.

\section{Conclusions}

Our results indicate that the biological effects of ETS in ovarian cancer might be mediated by the hypomethylated ETS motif, which induces the high expression of PARP1. Therefore, further studies are required to identify how the methylation of ETS affects PARP1 transcription and whether other factors could cooperate with ETS in controlling PARP1 gene expression. If we can clarify the mechanism behind high PARP1 expression from an epigenetic point of view, a more specific epigenetic therapy could be developed for ovarian cancer.

\section{Additional file}

Additional file 1: Clinical characteristics for the 10 BRCA-mutated serous ovarian cancer patients.

\section{Abbreviations}

PARP: Poly (ADP-ribose) polymerase; ETS: E26 transformation-specific; DNMT1: DNA methyltransferase 1.

\section{Competing interests}

The authors declare that they have no competing interests.

\section{Authors' contributions}

QY conceived the study. FFB and DL carried out data acquisition and interpretation. QY, FFB and DL drafted the manuscript. All authors read and approved the final manuscript.

\section{Author details}

'Department of Obstetrics and Gynecology, Shengjing Hospital, China Medical University, Shenyang 110004, China. 'Department of Physiology, Institute of Basic Medical Sciences, China Medical University, Shenyang 110001, China.

Received: 26 June 2012 Accepted: 25 February 2013

Published: 26 February 2013

\section{References}

1. Siegel R, Naishadham D, Jemal A: Cancer statistics 2012. CA Cancer J Clin 2012, 62:10-29.

2. Pruthi $\mathrm{S}$, Gostout BS, Lindor NM: Identification and Management of Women With BRCA Mutations or Hereditary Predisposition for Breast and Ovarian Cancer. Mayo Clin Proc 2010, 85:1111-1120.

3. Bryant HE, Schultz N, Thomas HD, Parker KM, Flower D, Lopez E, Kyle S, Meuth M, Curtin NJ, Helleday T: Specific killing of BRCA2-deficient tumours with inhibitors of poly(ADPribose) polymerase. Nature 2005, 434:913-917.

4. Farmer $\mathrm{H}, \mathrm{McC}$ abe $\mathrm{N}$, Lord CJ, Tutt AN, Johnson DA, Richardson TB, Santarosa M, Dillon KJ, Hickson I, Knights C, Martin NM, Jackson SP, Smith GC, Ashworth A: Targeting the DNA repair defect in BRCA mutant cells as a therapeutic strategy. Nature 2005, 434:917-921.

5. Barnett JC, Bean SM, Nakayama JM, Kondoh E, Murphy SK, Berchuck A: High poly (adenosine diphosphate-ribose) polymerase expression and poor survival in advanced-stage serous ovarian cancer. Obstet Gynecol 2010, 115:49-54.

6. Brustmann H: Poly(adenosine diphosphate-ribose) polymerase expression in serous ovarian carcinoma: correlation with p53, MIB-1, and outcome. Int J Gynecol Pathol 2007, 26:147-153.

7. Suzuki MM, Bird A: DNA methylation landscapes: provocative insights from epigenomics. Nat Rev Genet 2008, 9:465-476. 
8. Gong C, Tao G, Yang L, Liu J, Liu Q, Li W, Zhuang Z: Methylation of PARP-1 promoter involved in the regulation of nano-SiO2-induced decrease of PARP-1 mRNA expression. Toxicol Lett 2012, 209:264-269.

9. Gao A, Zuo X, Liu Q, Lu X, Guo W, Tian L: Methylation of PARP-1 promoter involved in the regulation of benzene-induced decrease of PARP-1 mRNA expression. Toxicol Lett 2010, 195:114-118.

10. Håkansson S, Johannsson O, Johansson U, Sellberg G, Loman N, Gerdes AM, Holmberg E, Dahl N, Pandis N, Kristoffersson U, Olsson H, Borg A: Moderate frequency of BRCA1 and BRCA2 germ-line mutations in Scandinavian familial breast cancer. Am J Hum Genet 1997, 60:1068-1078.

11. Simard J, Tonin P, Durocher F, Morgan K, Rommens J, Gingras S, Samson C, Leblanc JF, Bélanger C, Dion F, Liu Q, Skolnick M, Goldgar D, ShattuckEidens D, Labrie F, Narod SA: Common origins of BRCA1 mutations in Canadian breast and ovarian cancer families. Nat Genet 1994, 8:392-398.

12. Suter NM, Ray RM, Hu YW, Lin MG, Porter P, Gao DL, Zaucha RE, Iwasaki LM, Sabacan LP, Langlois MC, Thomas DB, Ostrander EA: BRCA1 and BRCA2 Mutations in Women from Shanghai China. Cancer Epidemiol Biomarkers Prev 2004, 13:181-189.

13. Das PM, Singal R: DNA methylation and cancer. J Clin Oncol 2004, 22:4632-4642

14. Gutierrez-Hartmann A, Duval DL, Bradford AP: ETS transcription factors in endocrine systems. Trends Endocrinol Metab 2007, 18:150-158.

15. Soldatenkov VA, Albor A, Patel BK, Dreszer R, Dritschilo A, Notario V: Regulation of the human poly(ADP-ribose) polymerase promoter by the ETS transcription factor. Oncogene 1999, 18:3954-3962.

16. Yao JJ, Liu Y, Lacorazza HD, Soslow RA, Scandura JM, Nimer SD, Hedvat CV: Tumor promoting properties of the ETS protein MEF in ovarian cancer. Oncogene 2007, 26:4032-4037.

17. Brenne K, Nymoen DA, Hetland TE, Trope' CG, Davidson B: Expression of the Ets transcription factor EHF in serous ovarian carcinoma effusions is a marker of poor survival. Hum Pathol 2012, 43:496-505.

18. Zampieri M, Passananti C, Calabrese R, Perilli M, Corbi N, De Cave F, Guastafierro T, Bacalini MG, Reale A, Amicosante G, Calabrese L, Zlatanova J, Caiafa P: Parp1 localizes within the Dnmt1 promoter and protects its unmethylated state by its enzymatic activity. PLoS One 2009, 4:e4717.

19. Ji Y, Tulin AV: The roles of PARP1 in gene control and cell differentiation. Curr Opin Genet Dev 2010, 20:512-518.

20. Esteller M, Silva JM, Dominguez G, Bonilla F, Matias-Guiu X, Lerma E, Bussaglia E, Prat J, Harkes IC, Repasky EA, Gabrielson E, Schutte M, Baylin SB, Herman JG: Promoter hypermethylation and BRCA1 inactivation in sporadic breast and ovarian tumors. J Natl Cancer Inst 2000, 92:564-569.

doi:10.1186/1471-2407-13-90

Cite this article as: $\mathrm{Bi}$ et al:: Promoter hypomethylation, especially around the E26 transformation-specific motif, and increased expression of poly (ADP-ribose) polymerase 1 in BRCA-mutated serous ovarian cancer. BMC Cancer 2013 13:90.

\section{Submit your next manuscript to BioMed Central and take full advantage of:}

- Convenient online submission

- Thorough peer review

- No space constraints or color figure charges

- Immediate publication on acceptance

- Inclusion in PubMed, CAS, Scopus and Google Scholar

- Research which is freely available for redistribution 